Revista General de Información y Documentación ISSN: 1132-1873

https://dx.doi.org/10.5209/rgid.66970

\title{
El Archivo de los Condes de Medellín, reposteros mayores del rey de Castilla
}

\author{
Antonio Sánchez González ${ }^{1}$
}

Recibido: 14 de abril de 2020 / Aceptado: 5 de mayo de 2020

Resumen. El objetivo de este artículo es presentar un fondo documental del Archivo Ducal de Medinaceli, la sección “Medellín”, con varios centenares de documentos del condado extremeño del mismo nombre que ostentó la familia Portocarrero, reposteros mayores de los reyes de Castilla desde la Edad Media, con conexiones con Portugal. Estos condes de Medellín entroncaron después, a partir del siglo XVII, con otras casas nobiliarias peninsulares, pasando su Archivo a incorporarse sucesivamente, primero en el siglo XVIII, al de los duques de Santisteban del Puerto y, definitivamente en 1818, al de los duques de Medinaceli. Por ambas vías llegaron documentos a este depósito, reagrupándose así el antiguo fondo, como descubre este artículo.

Palabras clave: Linaje Portocarrero; Condes de Medellín; repostero mayor; Reino de Castilla; Archivo Ducal de Medinaceli.

\section{[en] The Archive of the Counts of Medellín, “Royal Wardrobes” of the Castilian crown}

\begin{abstract}
This paper aims to analyze a collection of documents found in the "Medellín" section of the Medinaceli Dukal Archive, a large collection of over several hundred documents involving the county of Medellín, Extremadura. This collection was owned by the Portocarrero House, who worked as Royal Wardrobes for the kings of Castile since the Middle Ages and who had clear Portuguese connections. From the 17th century onwards, the Counts of Medellín related to other noble houses in Spain, which made their Archive pass into the hands of the Dukes of Santisteban del Puerto during the 18th century and, later, into the hands of the Dukes of Medinaceli in 1818 definitely. The documents which formed the socalled Medellín section come from the two houses we have just referred to, as this paper discovers.

Keywords: Portocarrero House; Counts of Medellín; "Royal Wardrobes”; Kingdom of Castille; Medinaceli Dukal Archive.
\end{abstract}

Sumario. 1. Introducción; 2. Casa, linaje y territorio: el condado de Medellín, un estado de los Portocarrero. 3. Análisis del fondo documental. 4. Conclusiones. 5. Referencias bibliográficas.

1 Universidad de Huelva. Departamento de Historia, Geografía y Antropología

E-mail: antonio.sanchez@dhis2.uhu.es 
Cómo citar: Sánchez González, A. (2020) El Archivo de los Condes de Medellín, reposteros del rey de Castilla, en Revista General de Información y Documentación 30 (1), 75-100.

\section{Introducción}

Los Portocarrero, una familia hidalga procedente de Galicia que pasó a Portugal al tiempo de constituirse en reino independiente con el infante D. Enrique y que en el siglo XIII retorna a Castilla, adquirieron en Extremadura un importante estado señorial, el condado de Medellín, como consecuencia de la conquista del territorio al Islam y consecuente política repobladora de los monarcas, así como de los vaivenes políticos durante las luchas civiles que tuvo el reino. Este estado extremeño estaba enclavado mayoritariamente al norte de la actual provincia de Badajoz -por la parte central- con incursión en la de Cáceres, un territorio cursado por el río Guadiana, con la tierra de Barros por el sur y la comarca de La Serena por el este.

El dominio había sido enclave realengo, ocupado por distintos miembros de la Casa real durante el siglo XIV, hasta que en el segundo cuarto del siglo XV el rey de Castilla Juan II lo convierte en señorío, por vía de mayorazgo, para D. Pedro Ponce de León, señor de Marchena, por privilegio de 1431. Su posesión no sería, sin embargo, demasiado prolongada pues los intereses patrimoniales del de Marchena estaban más orientados a la región andaluza, revirtiendo pronto el señorío de Medellín a la Corona castellana. Fue entonces cuando el propio Juan II lo entrega en 1445 a su favorito, el marqués de Villena D. Juan Pacheco, otra posesión efímera si tenemos en cuenta que, cuatro años después, el infante D. Enrique (futuro Enrique IV) concede el señorío a Rodrigo Portocarrero, una merced confirmada por el mismo rey Juan II en 1453.

El estado fue elevado a condado en 1456 por el rey Enrique IV, en la persona de su ya repostero mayor, el dicho Rodrigo Portocarrero, cargo de total confianza del monarca pues se encargaba, preferentemente, de la custodia de aquellos bienes de valor que le eran confiados por la Casa real. En adelante estos Portocarrero ejercieron el cargo de forma más honorífica que efectiva y, sobre todo, se dedicaron a administrar su patrimonio señorial.

El condado extremeño de Medellín pasó, entre 1720-1726, a la Casa de Santisteban del Puerto por vía judicial, tras sentencia favorable en el pleito sustanciado contra los marqueses de Aytona ante la chancillería de Granada. Y agregado a aquella se incorporaría en los inicios del siglo XIX a la Casa Ducal de Medinaceli hasta nuestros días.

Como consecuencia de ello, el Archivo condal de Medellín se transfirió a Madrid en el siglo XVIII para incorporarse, primero, al de Santisteban del Puerto en el palacio que estos tenían en la Plaza de San Pedro y, con él en 1818, al Archivo General de la Casa Ducal de Medinaceli en el majestuoso palacio que estos poseían en el Paseo del Prado. En tales unidades archivísticas superiores se acabó de organizar el fondo señorial de los condes de Medellín, bajo los parámetros establecidos por estos nobles en sus Archivos. Y, casualidades del destino, por ambas vías, las de Aytona y de Santisteban del Puerto, llegaron al Archivo Ducal de 
Medinaceli documentos del condado extremeño, reagrupándose así el fondo, como está en nuestros días, una primicia que ofrece este artículo.

Nuestro objetivo aquí no es otro que difundir los contenidos del archivo familiar de estos Portocarrero, condes de Medellín, además de perfilar su sistema de organización documental durante los siglos XVIII y XIX y trazar la evolución secular del fondo archivístico en ese tiempo, tras tratar primero la evolución histórica familiar de la Casa y su evolución hasta agregarse a los Medinaceli.

Para ello, metodológicamente, no solo hemos trabajado en el fondo documental aquí objeto de estudio, revisando sus inventarios y analizando las marcas dorsales de cada pieza documental, sino también en la documentación de referencia que se conserva en la Real Academia de la Historia, preferentemente la colección Salazar y Castro, así como en otras piezas sueltas del Archivo Histórico Nacional, Archivo de la Nobleza española y Arquivo Nacional da Torre do Tombo en Lisboa.

\section{Casa, linaje y territorio: el condado de Medellín, un estado de los Portocarrero}

El linaje Portocarrero ha quedado atribuido por los genealogistas, en sus orígenes, a la descendencia de D. García Alonso de León (1100- ? ), hidalgo de origen gallego y ricohombre de la monarquía asturiana-leonesa en tiempos del rey Bermudo III, atribuyéndole ser pionero en la utilización del patronímico a su descendiente Raimundo (o Ramón) García de Portocarrero, quien pasó a Portugal con el Conde D. Enrique de Borgoña y ahí quedó afincado al tiempo de la configuración del territorio como reino independiente, siendo tronco de los “Portocarreiro" portugueses ${ }^{2}$.

A mediados del siglo XIII regresan a Castilla algunos miembros de la familia, donde más tarde, la posteridad de aquel caballero adquiría, en quien fuera paje de cámara del rey Sancho IV de Castilla y León y luego mayordomo de Pedro I, Martín Fernández de Portocarrero (c.1326-1370), el señorío de Villanueva del Fresno (1336) y, por alianza con los Tenorio ${ }^{3}$, el de Moguer unos veinte años después (1356). El heredero de este patrimonio castellano fue Alonso Fernández Portocarrero ( $† 1384)$, de quien pasó a sus descendientes, por línea de primogenitura, formando la rama troncal del linaje en los sucesivos señores de Moguer y Villanueva del Fresno (González, 1976: 40-41), de la que se surgirían importantes casas nobiliarias ${ }^{4}$.

Pero el verdadero tronco de la Casa que nos ocupa se personaliza en Rodrigo Portocarrero I ( $\uparrow 1467)$, sobre el que los genealogistas no se ponen de acuerdo al remontarlo y conectarlo con aquellos ascendientes. Para unos, sería un hijo natural del señor de Moguer y Villanueva del Fresno Pedro Portocarrero Cabeza de Vaca y,

\footnotetext{
Este origen de la estirpe queda atribuido por Fernández, 1900: 305, García Carraffa, 1954: 72, $26-27$ y otros que siguen a Barcelos, 1640, como Felgueiras, 1940: XXIV, 166-169. Cfr. Peña, 2000.

3 Martin Fernández Portocarrero casó con María Tenorio, hija del Almirante de Castilla Alonso Jofre Tenorio.

4 Por ejemplo, la propia de los señores de Moguer más tarde convertidos en marqueses de Villanueva del Fresno y de Barcarrota, la de los condes de la Puebla del Maestre, la de los marqueses de Alcalá de la Alameda (véase Sánchez, 2019) o la de los marqueses de la Torre de las Sigardas (Fernández, 1900: 307).
} 
así, bisnieto del susodicho Alonso Fernández Portocarrero ${ }^{5}$; otros, sin embargo, con el mismo parentesco con éste, lo convierten -en versión más fiable- en hijo de otro Alfonso Fernández Portocarrero ${ }^{6}$.

En cualquiera de los casos, el hecho es que dicho Rodrigo Portocarrero sirvió a los reyes castellanos Juan II y Enrique IV durante gran parte del siglo XV y que estuvo casado, desde 1453, con $\mathrm{D}^{\mathrm{a}}$. Beatriz Pacheco (c. 1440-1491), una hija natural del célebre marqués de Villena D. Juan Pacheco y beneficiada en la dote de su padre con el lugar de Villarejo de Fuentes y otros dominios ${ }^{7}$.

En ese mismo año D. Rodrigo Portocarrero era confirmado por privilegio rodado de Juan II en la posesión del señorío extremeño de Medellín ${ }^{8}$, una villa que previamente le había concedido el infante D. Enrique -futuro rey Enrique IV- a través de sucesivas mercedes ${ }^{9}$.

Este dominio pacense había sido conquistado, primero, por el rey Fernando II de León en 1186 con la ayuda del maestre de Santiago Fernando Díaz ${ }^{10}$ y, definitivamente, por las huestes de Fernando III de Castilla-León en 1234 (Solano, 1650) ${ }^{11}$ cuando toda la región extremeña del sur caía en manos cristianas (Martínez, 1904: 299-310 y Clemente, 1990: 542). De toda la zona ocupada, solo los términos de Medellín, Herrera y Puebla de Alcocer pasaron a la Corona de Castilla; el resto fue distribuido entre la tierra realenga del concejo de Badajoz y las extensiones de las órdenes militares de Santiago, Alcántara y el Temple (Mazo, 1980: 44-46) ${ }^{12}$.

5 Esta ascendencia natural es atribuida, por ejemplo, por Garcia Carraffa, 1954: 72, 26-27.

6 Este origen de Rodrigo Portocarrero es el que señala López de Haro, 1622: I, 301, y el que recogemos nosotros en la tabla genealógica Medellín =Portocarrero= que hemos elaborado y que ilustra estas páginas.

7 Real Academia de la Historia (en adelante RAH), Colección Salazar y Castro (= Col S y C), n 20531: Escritura de dote dada en Segovia, 2 noviembre 1453. Y otra de dote y arras dada en Medina del Campo el 10 de marzo de 1454 (RAH, Col. S y C, nº 56008). Véase Fernández, 1900: 191.

8 Archivo Ducal de Medinaceli (en adelante ADM), Privilegios Rodados, no 92 (A.- original) y Medellín 1-5 (B.traslado). Cfr. Sánchez, 2009: 265. Otra copia auténtica en el Archivo Histórico de la Nobleza (en adelante SNAHN), Osuna, caja 139, $\mathrm{n}^{\text {os }}$. 82-84.

9 Véase ADM, Medellín, 1-1 a 4 (mercedes sobre el lugar por parte del infante entre julio y diciembre de 1449).

10 En 1188 el rey de Castilla Alfonso VIII, que invadió León y se hizo con varias poblaciones de aquel reino, concede las décimas de Medellín a la orden santiagueña, también por privilegio rodado (RAH, Col. S y C, nº 77736; también los nos. 77565 y 77603).

11 En 1247, cercando a Sevilla, el mismo rey otorga licencia a Payo Pérez Correa, maestre de Santiago, para construir una barca en Medellín para cruzar el río Guadiana (RAH, Col. S y C, nº 77822).

12 Inicialmente Medellín, tras la conquista, fue entregada también por Fernando III a la orden de Alcántara, como Magacela y otros lugares del partido de la Serena. Sin embargo, la Corona decidió muy pronto mantenerla como villa de realengo, apartándola de la orden. Véase Martínez, 1904: 413-414: transcripción de la donación de ciertas heredades en Medellín a la orden de Alcántara, 1234 (Ortega, 1759: XVI, 40-41). 
Tabla 1. Genealogía del linaje Acuña, señores y condes de Medellín. Elaboración propia

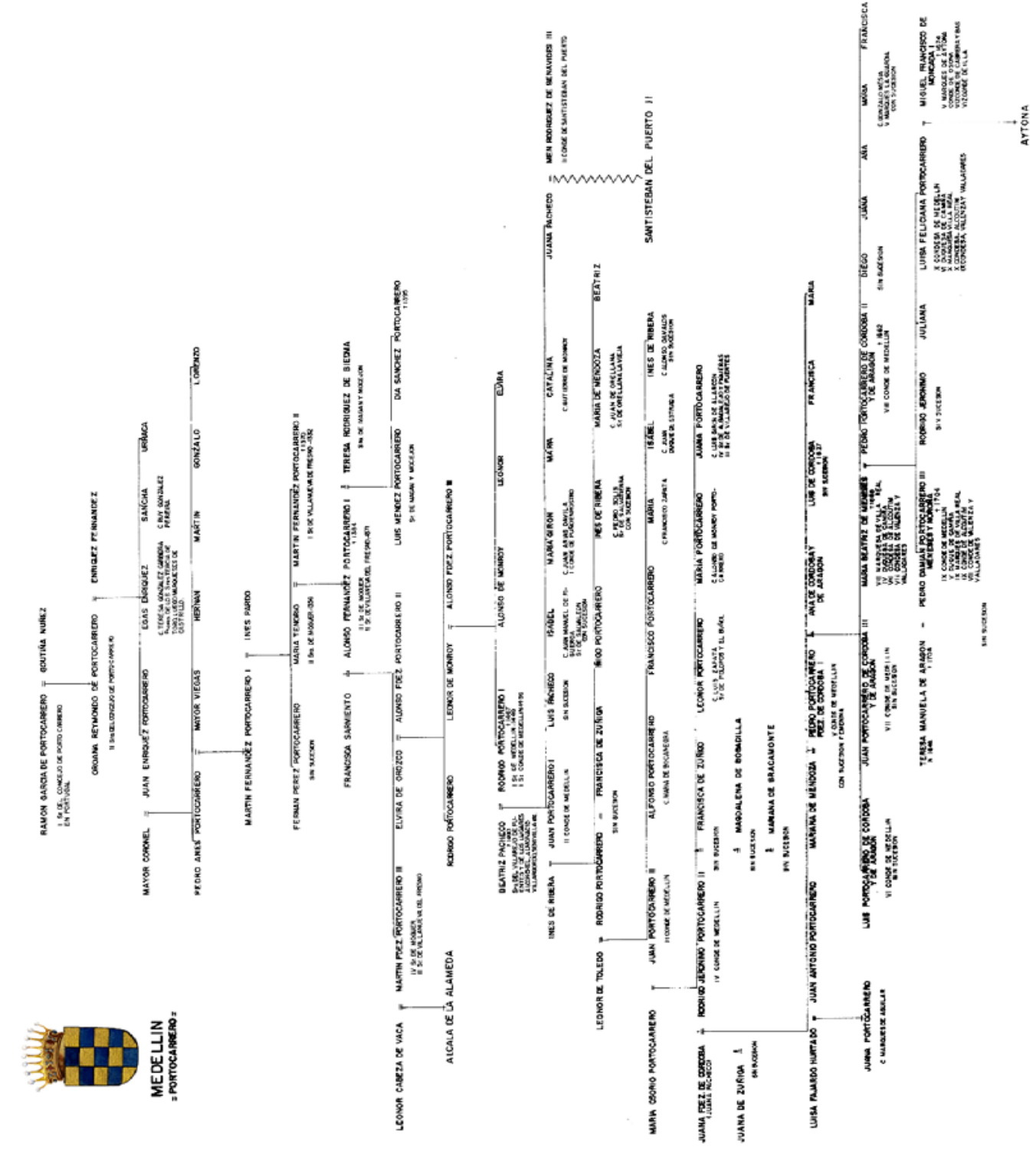

Y muy probablemente Medellín permanecería como enclave realengo hasta el segundo cuarto del siglo XV, si bien ocupado por distintos miembros de la Casa real durante la centuria anterior pues, en 1344, era señor del lugar -y también de 
Alburquerque- el caballero portugués João Afonso de Alburquerque (1304-1354) ${ }^{13}$, de quien pasaría a su segundogénito Martín Gil, también llamado Martín Eanes de Alburquerque (1325-1365), que sería ejecutado por orden del rey Pedro I de Castilla en $1365^{14}$. El monarca destruyó el castillo de Medellín en 1354, pero su hermanastro y sucesor en el trono castellano Enrique II de Trastámara lo donó en 1366, con el condado de Alburquerque, a otro hermano suyo, el infante D. Sancho de Castilla (1342-1374), quien, como señor de Medellín, reedificó el castillo en $1373^{15}$.

Más tarde, el monarca Juan II convierte aquel territorio en señorío, por vía de mayorazgo, para D. Pedro Ponce de León (1365-1448), V señor de Marchena, por real cédula de 8 de diciembre de $1429^{16}$, pero como sus intereses patrimoniales estaban más orientados a la región andaluza, pronto el mismo rey se lo permuta por el condado de Arcos, por privilegio rodado que otorgó en Medina del Campo el 24 de febrero de $1431^{17}$. Así, de nuevo, el señorío de Medellín retornaba a la Corona, aunque no sería por largo tiempo. Pues el rey Juan II concede de nuevo aquella tierra al poderoso marqués de Villena D. Juan Pacheco el 13 de septiembre de 1445 (Fernández, 1900: 150-156 y Franco, 2007: 606), otra posesión igualmente efímera pues el favorito regio permutó en 1449 con el príncipe D. Enrique la villa y castillo de Medellín por las de Chinchilla y Garcimuñoz, más próximas a sus posesiones en Belmonte y Villena ${ }^{18}$.

Ese mismo año se va a producir la ya aludida concesión del señorío a D. Rodrigo Portocarrero (†1467), yerno del último titular, confirmada por privilegio rodado del mismo rey en $1453^{19}$. Y poco después, el nuevo monarca Enrique IV elevaba este estado pacense a rango de condado, en la persona de su repostero mayor D. Rodrigo, por real provisión dada en Ávila el 20 de enero de $1456^{20}$.

El repostero mayor del rey ${ }^{21}$ era un oficial de máxima confianza de los monarcas que se encargaba en la Casa Real preferentemente del «repuesto o depósito», es decir, de la custodia de los objetos personales del monarca, junto con aquellos otros bienes de valor que el propio rey le confiara para su vigilancia en unos cofres o

13 Nieto del rey D. Dinis de Portugal y esposo de la señora de Meneses Da. Isabel de Meneses (RAH, Col. S y C, $\mathrm{n}^{\text {os }} .36807$ y 20829), pasó a Castilla siendo alférez mayor y canciller de su primo el rey Alfonso XI, ayo y mayordomo mayor del infante Pedro y, luego, valido del joven rey quien más tarde le retiró su confianza.

14 Con esta muerte se extinguió la línea principal de este linaje y el monarca castellano incorporó los bienes a la Corona (Braamcanp, 1927: 196.; Pizarro, 1987: 231-232 y 291, y 1999: I, 193-194; y Reglero, 2001: 125). Por su parte, su madre Isabel Téllez de Meneses se convirtió en la heredera universal de sus bienes en Portugal (Fernandes, 1972: 1455).

15 La historia de esta fortaleza en García, 2000. También es muy útil, para conocer estas vicisitudes, la obra de Pino, 1991.

16 RAH, Col. S y C, no 45287.

17 ADM, Medellín, 16-5-1 (es copia del original). Existe copia en carta plomada, suscrita en Valladolid a 25 junio de 1440 (RAH, Col. S y C, no 52690) y otra copia en SNAHN, Osuna, caja 139, $n^{\text {os }}$. 82-84.

18 SNAHN, Frías, caja 659 n ํ 26. Cfr. Franco, 2007: 614-615 y 643-648 (transcripción del documento).

19 ADM, Privilegios Rodados, $n^{\circ}$ 92. El documento original es de bellísima factura y está decorado con albanega naturalista.

20 ADM, Archivo Histórico (Títulos), leg. 272 n 35 -antigua caja de hierro $2 \mathrm{n}^{\mathrm{o}}$ 35-R-: A. original; y ADM, Medellín, 1-6: B.- traslado.

21 Los romanos llamaron a estos oficiales comes castrensis, ya que eran los encargados de los castrensianos (que ponían la mesa al emperador), de los lampadarios (encomendados de las luces) y de los cellarios (que cuidaban la despensa). 
arcones (Salazar, 2000: 270) ${ }^{22}$. Ya Alfonso X el Sabio en Las Partidas señalaba también algunas de sus funciones, con estas palabras:

"Repostero es otrosí oficial que tiene grant lugar para guardar el cuerpo del rey, et ha este nombre porque él ha de tener las cosas que el rey manda guardar en poridat; et aun ha de tener otras cosas guardadas que tañen a la guarda del cuerpo del rey, así como la fruta, et la sal, et los cuchiellos con que tajan ante él, et algunas cosas otras que son de comer..."23.

En tiempos de D. Rodrigo Portocarrero, el repostero mayor del rey tenía a su cargo varios reposteros menores (de camas, de capilla, de plata, de estrados y mesa...). Según Salazar y Acha, el salario del repostero mayor ascendía entonces a 12.000 maravedís anuales, cantidad equivalente a la percibida por el ballestero mayor del rey y por su maestresala (Salazar, 2000: 270-271) ${ }^{24}$. Se trató de un cargo efectivo durante la baja Edad Media, para convertirse luego en honorifico en el reino de Castilla (en Aragón desapareció) asumiendo sus funciones el camarero mayor del rey (Ladero, 1998: 336) ${ }^{25}$.

El recién constituido condado metelinense, con otras posesiones de la Casa, fue incluido en el mayorazgo que, con licencia real ${ }^{26}$, el conde y su esposa $\mathrm{D}^{\mathrm{a}}$. Beatriz Pacheco $^{27}$ fundaron el 20 de mayo de 1462 por escritura suscrita ante Rodrigo Álvarez de Espinel, escribano de Cámara y notario de los Reinos, agrupando

“...mi Villa de Medellín, con su castillo e fortaleza, e vassallos, e tierra e término, e jurisdicción civil y criminal, alta e baxa, mero y mixto imperio; e con todas las rentas, pechos e derechos, e vassallos e otras cosas a la dicha villa e al sennorío de ello pertenecientes, e con el dicho título de Condado, y ... otros bienes e rentas que les pertenecen y expressan en dicha cláusula. Y la villa de Villarejo de Fuentes, que entonces pertenecía a dicha sennora Doña Beatriz Pacheco, y vna merced de 24 maravedís de renta”. ${ }^{28}$

Cinco años después, por muerte de D. Rodrigo, sucedía en este mayorazgo, como II Conde de Medellín, su primogénito D. Juan Portocarrero I (1455-1528), repostero

22 Como afirma Costa Gomes, el repostero era muy similar al “wardrobe” inglés del siglo XIII (Gomes, 1995: 26). En Portugal, se cita este cargo por primera vez en el testamento del rey Sancho I (1209), teniendo en aquella Corte importantes atribuciones financieras ligadas al tesoro real, además de encargarse de la guarda y custodia de los objetos más valiosos de la cámara del rey (Labrador, 2006: I, 135). Para la evolución del oficio en Castilla, véase Grassotti, 1987: 41-75.

23 Alfonso X, Partida II, título I, ley VI, edic. 1972: II, 68.

24 Añade el autor que si alguien asesinaba al repostero mayor de la Casa Real debía sufrir igual pena que si hubiera dado muerte a uno de los alcaldes del rey.

25 Véase, además, Grassotti, 1987.

26 La licencia del propio rey está fechada en Valladolid el 15 de noviembre de 1460 (RAH, Col. S y C, nº 56127), que confirma diez días después (RAH, Col. S y C, nº 56128).

27 Sobre esta señora, véanse Cabrera, 1985 y García, 1997.

28 ADM, Medellín, 2-11; SNAHN, Osuna, caja 1619, nº 6; y RAH, Col. S y C, nº 56126. Véase CORTÉS, 2016. Una vez viuda la condesa de Medellín, casó Da. Beatriz con Alonso de Silva y Acuña, II Conde de Cifuentes (RAH, Col. S y C, n 20512; cfr. FRANCO, 2009: 177-178), y de este mayorazgo quedaría apartado, desde 1483, el lugar de Villarejo de Fuentes. 
mayor del rey Enrique $\mathrm{IV}^{29}$, al parecer, no sin tener que sufrir grandes disturbios por la posesión del estado en litigio con su propia madre $\mathrm{D}^{\mathrm{a}}$. Beatriz Pacheco ${ }^{30}$, tal vez "a causa de distinta adscripción partidista en los conflictos sucesorios [al trono de Castilla] que tomaron un nuevo cariz a partir de entonces” (Cabrera, 1985: 529-531).

En ese tiempo el condado extremeño tenía perfilados sus límites territoriales en las fértiles tierras de las Vegas Altas del Guadiana, formando una comunidad compuesta por siete villas y tres aldeas, enclavada mayoritariamente al norte de la actual provincia de Badajoz -por la parte central- con incursión en la de Cáceres. Los términos pacenses que incluía, aparte de Medellín (con su poderoso castillo desde el que se controlaban aquellas huertas y campiñas y el importante paso del río Guadiana), eran Don Benito -con Don Llorente en proceso de despoblamiento-, Mengabril, Rena, Villar de Rena, Manchita, Guareña, Cristina y Valdetorres. Por el oeste le servían de límites la Sierra Bermeja y el río Burdallo, cerca de Mérida (encomienda de Santiago). Por el sur, la zona oriental de la tierra de Barros (encomienda santiaguista de Alange). Y, por el este, la comarca de La Serena (encomienda calatrava de Magacela). El condado estaba, así, cursado por las aguas del Guadiana de E-O, y por algunos de sus afluentes (Ruecas, Ortiga y Guadalmez), aparte del canal de Orellana que atravesaba la cacereña Miajadas al norte, lindera con la Tierra del alfoz de Trujillo y la encomienda de Montánchez de la orden de Santiago. En conjunto el condado ocupaba una extensión de unos 1195’17 kms².

Al segundo Conde de Medellín, le sucedería más adelante su nieto Juan Portocarrero y Toledo II (1505-1546), casado con María Osorio Portocarrero, y luego el hijo de estos, Rodrigo Jerónimo Portocarrero y Osorio (1540-1600), IV Conde, además de mayordomo y repostero mayor del rey ${ }^{31}$.

Ya en el siglo XVII, tras varias sucesiones efímeras, recaía el estado desde 1634 en el VIII Conde D. Pedro Portocarrero Fernández de Córdoba y Aragón II (†1662), también repostero mayor de la Casa real de Castilla y caballerizo mayor de la reina española $D^{a}$. Mariana de Austria ${ }^{32}$. Este conde contrajo nupcias con $D^{a}$. María Brites (o Beatriz) de Meneses y Noroña (†1668), única superviviente de la Casa de los Meneses de Portugal, marqueses de Vila Real y otros títulos en aquel reino ${ }^{33}$, en 1641 degollados públicamente en Lisboa al tiempo de la revuelta por la Restauración de la independencia de Portugal con la entronización de la Casa de Bragança en aquel reino,

29 El cargo de repostero se lo había concedido el monarca en 1463 (RAH, Col. S y C, nº 56129).

30 Se cuenta que, a tal efecto, $\mathrm{D}^{\mathrm{a}}$. Beatriz de Pacheco mantuvo encerrado durante cinco años a su hijo Juan en una mazmorra de la torre norte del castillo de la villa de Medellín, suceso que originó la leyenda del encierro del Conde (véase Almagro; García, 2013). Sobre las tensas relaciones maternofiliales de Da . Beatriz y el joven Juan, sustanciadas en 1480 mediante una concordia (RAH, Col. S y C, n ${ }^{\text {os }} .40431$ y 55999) y capitulación de 1482 (RAH, Col. S y C, ${ }^{\text {os }}$. 55989 y 55988).

31 Véase la aludida tabla genealógica Medellín =Portocarrero= que ilustra estas páginas.

32 La propia reina le encarga en 1667 la ejecución de la reforma del Consejo de Indias (RAH, Col. S y C, $\mathrm{n}^{\text {os }}$. 40784).

33 A principios del siglo XV fue titular de esta Casa en Portugal D. Pedro de Meneses y Portocarrero ( $† 1437)$, capitán general de Ceuta desde el mismo momento de su conquista en 1415 y a partir de 1424, además, I Conde de Vila Real, estado también de la familia "Portocarreiro" que él había heredado de su madre, Da. Mayor Portocarrero y Silva, en calidad de señorío. Véase Arquivo Nacional Torre do Tombo (ANTT), A Cartório da Nobreza /001- Nobiliários /19: Livro do Armeiro-mor (1509), João do Cró (o João du Cros): Armas de Portocarreiro, fol. $122-1^{\text {o }}$; y Genealogias Manuscritas, n. ${ }^{\circ}$ 86: Nobiliário das famílias ilustres de Portugal ordenado por António Peixoto de Queirós e Vasconcelos (1775), letra P, tomo $2^{\circ}$, fols. 234-240 (Portocarreiro). Más datos en Sánchez, 2020 (en prensa). 
por lo que los sucesivos condes de Medellín se titularían además, por entonces, Duques de Camiña, Marqueses de Villa Real y Condes de Alcoutim, Valenza y Valladares ${ }^{34}$.

Dos hijos de este matrimonio heredarían sucesivamente, a partir de 1662, los mayorazgos de la Casa. Primero el varón, Pedro Damián Portocarrero y Meneses III (1640-1704), IX Conde de Medellín, además de V Duque de Camiña, IX Marqués de Villa Real, IX Conde Alcoutim y VIII de Valenza y Valladares. Fue, como su padre, repostero mayor del rey y se convirtió en uno de los valedores más importante del partido francés en la Corte española como agente del rey Luis XIV para defender las aspiraciones del Delfín francés a la sucesión del trono español ${ }^{35}$. Tras él, que falleció soltero en 1704, sucedió en la Casa su hermana $\mathrm{D}^{\mathrm{a}}$. Luisa Feliciana Portocarrero de Meneses y Noroña (1643-1705), además de X Condesa de Medellín, por entonces marquesa viuda de Aytona por el matrimonio que había contraído en 1671 con Miguel Francisco de Moncada y Silva, V Marqués de Aytona y de la Puebla de Castro, Conde de Osona, Vizconde de Cabrera, de Bas e Illa, Gran Senescal y Maestre Racional de Cataluña.

Para dicha posesión, Da. Luisa Feliciana hubo de rivalizar con su pariente D. Francisco de Benavides Dávila y Corella, IX Conde de Santisteban del Puerto ${ }^{36}$. Y aunque este tomó posesión de Medellín en 1704 tras la muerte de D. Pedro Damián ${ }^{37}$, seis años después retornaría el condado a la línea de $\mathrm{D}^{\mathrm{a}}$. Luisa Feliciana, ahora en posesión de su hijo, el también VI Marqués de Aytona D. Guillén Ramón de Moncada y Portocarrero (1671-1727), por sentencia favorable en su favor ${ }^{38}$. Sin embargo, se trataría de una sucesión efímera en lo concerniente a Medellín por cuanto, en la reanudación de los pleitos con los condes de Santisteban del Puerto, estos obtuvieron sentencia favorable de la chancillería de Granada el 15 de marzo de $1720^{39}$, con ratificación posterior el 13 de abril de $1726^{40}$ y un año después en la Sala de mil y quinientas ${ }^{41}$.

Esta pérdida significó que, a la muerte en 1727 del XI Conde D. Guillén Ramón, el estado extremeño no llegara a poder de su hija y sucesora, la VII Marquesa de Aytona $\mathrm{D}^{\mathrm{a}}$. María Teresa de Moncada y Benavides, esposa desde cinco años atrás del marqués de Cogolludo $-\mathrm{y}$, como tal, futuro duque de Medinaceli- D. Luis

34 En Portugal fueron confiscados los estados de la familia Meneses, pero esos títulos fueron castellanizados en España por Felipe IV, como premio a su fidelidad a la causa española, aunque obviamente de carácter honorifico por cuanto que tales dominios portugueses no tenían ningún respaldo señorial ni patrimonial en Portugal al ser denegada la solicitud de restitución del patrimonio planteada por los condes de Medellín.

35 Una faceta de la vida de este duque de Camiña es la recogida por Morel-Fatio, 1904: 211-228. Véase también la serie de manuscritos del Archivo Histórico Nacional (AHN), Consejos, lib. 2752, lib. 2756, fols. 23, 43, leg. 5240, exp. 67; Órdenes Militares, Alcántara, exp. 1214 y Expedientillos, 13.911.

36 Un litigio iniciado por el conde de Santisteban -y que seguiría luego su hijo- con su yerno el VI Marqués de Aytona D. Guillén Ramón de Moncada (1671-1727), tras la muerte en 1704 de su cuñado el conde de Medellín D. Pedro Damián Portocarrero y Meneses (Ribot, 2018: 28).

37 ADM, Medellín, 2-2.

38 ADM, Medellín, 14-1-1.

39 Véase ADM, Medellín, 11-5.

40 Véase ADM, Medellín, 2-9.

41 ADM, Medellín, 2-10. 
Antonio Fernández de Córdoba y Spínola de la Cerda $(1704-1768)^{42}$, pese a las reclamaciones que realizó el matrimonio.

Quien sí sucedía en el dominio pacense de los Portocarrero era el X Conde -y luego I Duque- de Santisteban del Puerto, D. Manuel de Benavides y Aragón (16831748), posesionándose del mismo el 8 de julio de $1726^{43}$, como XII Conde de Medellín, en alegación a su derecho sucesorio como descendiente directo de $\mathrm{D}^{\mathrm{a}}$. Juana Portocarrero Pacheco, hermana del segundo Conde de Medellín ${ }^{44}$. Tras él le sucedió su hijo Antonio de Benavides y de la Cueva (1714-1782) y, luego, su nieta Joaquina María de Benavides y Pacheco (1746-1805), XIV Condesa de Medellín y III Duquesa de Santisteban del Puerto. Esta señora es la que lleva los títulos y estados a la Casa Ducal de Medinaceli como esposa que fue de D. Luis María Fernández de Córdoba y Gonzaga, XIII Duque de Medinaceli, heredando ambas casas nobiliarias, con sus numerosos títulos y estados agregados, el primogénito del matrimonio D. Luis Joaquín Fernández de Córdoba y Benavides (1780-1840), XV Conde de Medellín, XIV Duque de Medinaceli y IV de Santisteban del Puerto.

Fue así como bajo la representatividad de la Casa de Santisteban, y por la misma vía que ésta, entró a formar parte el condado de Medellín en la Casa Ducal de Medinaceli en los inicios del siglo XIX ${ }^{45}$.

Tabla 2. Titulares de la Casa Condal de Medellín. Elaboración propia

\begin{tabular}{|l|c|}
\hline TITULARES & PERIODO \\
\hline I. Rodrigo Portocarrero y Monroy & $1456-1467$ \\
\hline II. Juan Portocarrero y Pacheco I & $1467-1528$ \\
\hline III. Juan Portocarrero y Toledo II & $1528-1546$ \\
\hline IV. Rodrigo Jerónimo Portocarrero y Osorio & $1546-1600$ \\
\hline V. Pedro Portocarrero Fernández de Córdoba I & $1600-1622$ \\
\hline VI. Luis Portocarrero Fernández de Córdoba y Aragón & $1622-1624$ \\
\hline VII. Juan Portocarrero Fernández de Córdoba y Aragón & $1624-1634$ \\
\hline VIII. Pedro Portocarrero Fernández de Córdoba y Aragón II & $1634-1662$ \\
\hline IX. Pedro Damián Portocarrero Meneses Noroña III & $1662-1704$ \\
\hline X. Luisa Feliciana Portocarrero y Meneses & $1704-1705$ \\
\hline XI. Guillén Ramón de Moncada y Portocarrero & $1705-1720$ \\
\hline XII. $\quad$ Manuel de Benavides y Aragón & $1720-1748$ \\
\hline XIII. Antonio de Benavides y de la Cueva & $1748-1782$ \\
\hline XIV. Joaquina María de Benavides y Pacheco & $1782-1805$ \\
\hline
\end{tabular}

42 En 1739 sucedería en los estados de esta importante Casa nobiliaria española convirtiéndose, por derecho propio, en XI Duque de Medinaceli y de Segorbe, XII de Cardona, IX de Alcalá de los Gazules, X de Feria, X Marqués de Priego y otros títulos agregados, siete veces Grande de España (Sánchez, 2014: 76).

43 ADM, Medellín, 2-9 (2).

44 Véase este parentesco familiar que le permitió al conde de Santisteban el disfrute del condado de Medellín en la genealogía Santisteban del Puerto =Biedma \& Benavides= (Sánchez, 2015: apéndice final).

45 Para la evolución familiar de los condes de Medellín desde el siglo XVIII hasta nuestros días véase la genealogía Priego =Fernández de Córdoba= (Sánchez, 2015: apéndice final). 


\begin{tabular}{|l|c|}
\hline XV. Luis Joaquín Fernández de Córdoba y Benavides & $1806-1840$ \\
\hline XVI. Luis Tomás Fernández de Córdoba y Ponce de León & $1840-1873$ \\
\hline XVII. Luis María Fernández de Córdoba y Pérez de Barradas & $1873-1879$ \\
\hline XVIII. Luis Jesús Fernández de Córdoba y Salabert & $1880-1956$ \\
\hline $\begin{array}{l}\text { XIX. Victoria Eugenia Fernández de Córdoba y Fernández de } \\
\text { Henestrosa }\end{array}$ & $1959-2013$ \\
\hline $\begin{array}{l}\text { XX. Victoria Elisabeth de Hohenlohe-Langenburg y Schmidt- } \\
\text { Polex }\end{array}$ & $2018 \ldots$ \\
\hline
\end{tabular}

\section{Análisis del fondo documental}

\subsection{Formación del Archivo condal de Medellín}

Los señores y condes de Medellín, desde la creación de su Archivo allá por el siglo $\mathrm{XV}$, mantuvieron los documentos en la villa extremeña del mismo nombre, cabecera de aquel estado ${ }^{46}$, inicialmente dentro de su poderoso castillo, lo que se puede constatar por los diversos inventarios o relaciones de documentos que de estos fondos se hicieron desde entonces ${ }^{47}$.

Tampoco descartamos la permanencia temporal de los documentos del condado en otros inmuebles señoriales que tenían los Portocarrero de Medellín en su villa. Al conocido como "Palacio ducal", situado en la calle a la que daba nombre, inmueble que fue ejemplo de la arquitectura palacial de fines del siglo XVI -de la que aún se conserva, muy deteriorada, su fachada de sillería-, debió bajar el Archivo condal desde la fortaleza- en el siglo XVII ${ }^{48}$, donde debió permanecer hasta la agregación del condado a la Casa de Santisteban del Puerto, ya en el siglo XVIII.

Tras la muerte, en 1727, del marqués de Aytona D. Guillén Ramón de Moncada y Portocarrero, VII Duque de Camiña y XI Marqués de Villa Real, al pasar los estados de dichas Casas -salvo el de Medellín-, a su hija María Teresa de Moncada, consorte del futuro duque de Medinaceli, no sería obviamente trasladado el fondo del condado extremeño al Archivo que estos señores poseían en Madrid (Sánchez, 2014: 77-79) ${ }^{49}$, salvo algunos documentos que le sirvieron para su defensa en el largo pleito sostenido por la sucesión de los estados ${ }^{50}$. Cosa diferente ocurriría en algún momento con los documentos de la Casa de Camiña que, procedentes de Medellín donde permanecían-, pasarían en su totalidad a depositarse en el majestuoso palacio

46 Véase Sánchez, 2015: 94-96.

47 Véase ADM, Medellín, 9-8 y 14-1 y 3 bis. En este Archivo también permanecieron durante algún tiempo los fondos portugueses de los duques de Camiña y marqueses de Villa Real, con quienes se vincularon los condes de Medellín a mediados del siglo XVII (vid. ADM, Medellín, 14-1: Inventario firmado por Diego Ruiz de Montemayor. Medellín, 28 julio 1703). Más datos en los trabajos de Sánchez, 1990: 83-95 y 2020 (en prensa).

48 Otra casa palaciega que labraron los condes de Medellín en la villa, fuera de la muralla (actual número 2 de la plaza de España), de clara estructura barroca del siglo XVIII, por su parte pudo servir a partir de esa centuria para albergar los fondos de la contaduría de aquel estado pacense, ya vinculado a la Casa de los duques de Santisteban del Puerto. Una descripción de esta casona en Sánchez, 205: 96-97.

49 Fortuitamente, en 1818, a ese mismo palacio de Medinaceli llegará también el Archivo de los Condes de Medellín, del que venimos tratando, como profundizamos de inmediato.

50 De ahí lo de la duplicidad de fondos, a los que nos referiremos después, sobre el estado de Medellín. 
madrileño que tenían los Medinaceli-Aytona en la confluencia del Paseo del Prado con la Carrera de San Jerónimo (Sánchez, 2020), ya extinto.

\subsection{Agregación a unidades archivísticas superiores}

Al mismo Madrid, en distinta sede y algo más tarde, llegaría también el grueso del Archivo Condal de Medellín, procedente de la propia villa extremeña, a raíz de obtener por vía judicial aquel estado el entonces IX Conde de Santisteban del Puerto D. Manuel de Benavides y Aragón mediante las referidas sentencias de la chancillería de Granada, ratificadas en 1630 por la Sala de mil y quinientos ${ }^{51}$.

El Archivo de la Casa de Santisteban del Puerto -ducal, desde 1739, al recibir este título el propio D. Manuel de Benavides-, tenía su sede en la casa principal o “Casa Grande” que poseía la familia frente a la iglesia de San Pedro el Viejo, con esquina a la calle del Nuncio ${ }^{52}$. Y, por entonces, los duques de Santisteban aplicaron una política de concentración archivística ordenando las transferencias hasta aquel edificio madrileño de los numerosos fondos documentales que la Casa tenía repartidos por sus numerosos estados señoriales ${ }^{53}$. De ahí que fueran llegando paulatinamente hasta los depósitos de aquella casa-palacio los diferentes Archivos de esos diversos estados agregados entre 1720 y $1751^{54}$, principalmente por los años treinta, como fue el caso del fondo del condado extremeño llegado a los Santisteban del Puerto tras reñidos y largos pleitos.

Más adelante, a raíz del enlace matrimonial contraído en 1764 entre la futura XIV Condesa de Medellín y III Duquesa de Santisteban del Puerto, Da. Joaquina María de Benavides y Pacheco (heredera de la Casa en 1782) con el futuro XIII Duque de Medinaceli y otros títulos ${ }^{55}$, D. Luis María Fernández de Córdoba y Gonzaga (heredero de su Casa en 1789), se fraguaría la unión de ambas importantes casas nobiliarias españolas y, consecuencia de ello, se propiciaría la ulterior integración de ambos Archivos generales en un depósito único.

El heredero de ambas casas nobiliarias, con sus numerosos títulos y estados agregados, durante los primeros años del siglo XIX fue -según dijimos- el

51 ADM, Medellín, 2-9 y 10.

52 Sobre esta casa-palacio, véase ADM, Santisteban, 28-12 a 30. Cfr. Sánchez, 2015: 109-112.

53 Estos duques de Santisteban del Puerto también eran marqueses de Solera (de la Casa “De la Cueva”), condes de Cocentaina (de los “Corella” valencianos), señores de Villafranca de la Sierra, marqueses de Las Navas y condes del Risco (de la familia “Dávila”), marqueses de Malagón y sus señoríos vinculados de Fernán Caballero y Paracuellos del Jarama (de los “Arias Pardo-Tavera”), condes de Villalonso (de los “Ulloa”), condes de Castellar de la Frontera y señores de El Viso del Alcor (de los “Arias de Saavedra”), además de condes de Medellín (de estos "Portocarrero" extremeños).

54 Véase todo el proceso de concentración archivística de los diversos fondos en Sánchez, 2015: 103-108. El 2 de agosto de 1735 el aún conde de Santisteban D. Manuel de Benavides emite una orden desde Nápoles para que los administradores de sus estados (bajo cuya custodia aún quedaban sus respectivos fondos) remitiesen las escrituras a Madrid (ADM, Santisteban, 39-2-2).

55 Estos duques de Medinaceli eran también duques de Alcalá de los Gazules, marqueses de Tarifa y condes de los Molares (de los “Enríquez de Ribera”, Adelantados mayores de Andalucía), duques de Segorbe y condes de Ampurias (de la casa real de Aragón), duques de Cardona (de los “Folc de Cardona”) y sus títulos agregados de marqueses de Pallars, condes de Prades y barones de Entenza, vizcondes de Vilamur, etc., duques de Lerma y marqueses de Denia (de los “Sandoval y Rojas”), marqueses de Santa Gadea (de los “Manríquez de Padilla”, adelantados mayores de Castilla), condes de Buendía (de los “Acuña”), entre otros. 
primogénito de aquel matrimonio, D. Luis Joaquín Fernández de Córdoba y Benavides (1780-1840), XV Conde de Medellín, XIV Duque de Medinaceli y IV de Santisteban del Puerto.

Así, pasado el convulsivo período de la Guerra de la Independencia española (1808-1814), hasta al Archivo Ducal de Medinaceli -ubicado en aquel referido palacio del Paseo del Prado- llegó en 1818, desde aquella Casa Grande de la Plaza de San Pedro, la documentación del condado de Medellín unida al Archivo de Santisteban del Puerto.

Y, en adelante, el fondo del condado de Medellín que aquí tratamos ya no abandonaría nunca el Archivo Ducal de Medinaceli, radicando tanto en Madrid (1818-1961) como después en la “Casa de Pilatos” de Sevilla (1961-1995) y, por último, en Toledo -desde 1995-, con sede en el Palacio Tavera (antiguo Hospital de San Juan Bautista), donde hoy permanece.

\subsection{Organización y descripción documental}

El principal artífice inicial de las tareas orgánicas y descriptivas sobre los fondos archivísticos de la Casa de Santisteban del Puerto, al que quedaría inicialmente integrado el condal de Medellín, fue el archivero D. Manuel Antonio Brochero $(1735-1773)^{56}$.

Conocemos su labor por un informe que le requirió el marqués de Solera, heredero de la Casa, para remitirlo a Italia al conde, su padre, donde por entonces servía al rey de Nápoles (futuro Carlos III de España), para mantenerle informado ${ }^{57}$. Dicho informe, autógrafo y firmado por Brochero, aunque carece de fecha, debió haberlo realizado entre 1735 y $1737^{58}$. Del mismo se desprende el estado de disposición documental de los fondos por entonces en el depósito madrileño de los Santisteban señalando, al respecto, que

"Por no caver [sic] más cajones en esta pieza [del Archivo], están en un estante los papeles de las Navas, Ávila, Villafranca, Medellín, Cocentaina y la Encomienda, pero reconocidos, puestos en legajos, y separados para su busca, pero no en otra forma" 59 .

Esta mención al fondo Medellín viene a confirmarnos que el Archivo condal ya había llegado a la Casa Grande madrileña de los Santisteban en ese tiempo, escasos cinco años después de que los Benavides ganaran judicialmente la titularidad de dicho estado extremeño a los marqueses de Aytona. Había, pues, una sección "Medellín", entre las 17 que componían por entonces el Archivo Ducal de

56 Véase Sánchez, 2015: 113-139. Más adelante, en esta misma fase inicial, prosiguió estas labores en el depósito archivístico el también archivero D. Manuel de Terán (1783-1802).

57 Al ocupar, en 1734, el trono de Nápoles el infante don Carlos (como Carlos VII de Nápoles), el entonces conde de Santisteban D. Manuel de Benavides -por recomendación de la reina Isabel de Farnesio, madre del nuevo rey napolitano- acudió a Nápoles como tutor del joven monarca y allí será su principal ministro hasta 1738, año en que regresa a Madrid.

58 ADM, Santisteban, 39-2 (exped. 2). Transcrito el informe en Sánchez, 2015: 267-268 (apéndice documental nº 6).

59 ADM, Santisteban, 39-2 (exped. 2), fol. 2. 
Santisteban (una para cada uno de los estados y dominios señoriales) ${ }^{60}$, colocada en un estante del depósito y no en cajones o "papeleras".

En estricta aplicación del principio de respeto a la procedencia de los fondos, quedó conformado el organigrama del Archivo, procediendo a la clasificación archivística el archivero Brochero describiendo algunas secciones (entre las que se incluye la de Medellín) pieza a pieza, cada una en su envoltura, donde anotó los extractos (“de mi puño") ${ }^{61}$. Pese a la amplitud desorbitada de algunas regestas, que se convierten en casi una transcripción de la pieza documental ${ }^{62}$, en general, estas relaciones de contenido adolecieron de alguna imprecisión ${ }^{63}$.

A continuación, el archivero formó series con la documentación de cada fondo, unas series por lo general demasiado ambiguas, genéricas y concisas o poco aclaratorias ( "títulos de propiedad", "títulos de posesión”, "pertenencias de...", "papeles inútiles”, "preeminencias”, etc.), junto a otras más precisas (“cuentas”, "censos", "patronatos", “dotes y arras", etc.).

Luego se procedió a la ordenación de los documentos siguiendo un criterio cronológico, que se combinó con otro numérico, pues cada escritura así ordenada recibió un número correlativo dentro de su serie. Y se formaron legajos con los documentos ordenados, que también se enumeraron correlativamente.

Fruto de este trabajo orgánico desarrollado por Brochero en el depósito documental de los Benavides en Madrid fue la elaboración de 15 tomos inventarios, donde quedó refrendada toda su tarea archivística. La finalidad de estos inventarios nos la presenta el propio Manuel Antonio Brochero indicándonos que tenían esta triple funcionalidad:

"para el régimen del Archivo, para la busca de papeles; para el de la Contaduría, para que la conste la hacienda; y para que respectivamente sepa la Secretaría los patronatos, provisiones y regalías de la Casa" ${ }^{64}$.

60 Además de esta sección Medellín, las restantes secciones del depósito introducidas en cajones o papeleras -una por sección-: tres para el estado del Castellar (El Viso, Castellar y Sevilla), cuatro para el estado de Malagón (Paracuellos, Malagón, Sevilla y Toledo), cinco para el estado principal de Santisteban del Puerto (Solera, Santisteban, Espelúy, Ibros y Jaén), tres para el estado de Las Navas (Villafranca, Las Navas y Ávila) y una última para el estado de Villalonso. De inmediato se redujeron las secciones a 15, al integrarse los papeles del estado de Castellar de la administración de Sevilla en la de El Viso, por un lado, y de la administración de Toledo en la de Malagón, para el caso de este estado manchego, por otro.

61 ADM, Santisteban, 39-2 (exped. 2). Informe del estado del Archivo en torno a 1735. Añade Brochero en este documento autógrafo suyo: "haviendo leydo más de 50.000 ojas [...] para sacar la substancia". Estas regestas descriptoras solían ser bastante amplias, lo que en muchos casos le obligó a utilizar doble papel como envoltura o "guarda” de la unidad documental.

62 Vid. ADM, Partido de Ávila, 6-13 (antes Medinaceli, 168-13). Cfr. Inventario del Partido de Ávila, págs. 513 a 640 (regesta del doc. aludido).

63 Ello obligó en el futuro a renovar estas regestas imprecisas de Brochero, mejorándolas de contenido (Vid. ADM, Partido de Ávila, 16-51 (antes Medinaceli, 178-51): nota archivística que encabeza la serie). Y ello, además, dejó secuelas en los inventarios en forma de tachaduras y adiciones (Vid. Libro del Estado de Medellín, págs. 1-7; o Libro del Partido de Ávila, pág. 1.323).

64 ADM, Santisteban, 39-2 (expd. 2). Ello quiere decir que estos instrumentos de descripción del Archivo General de Santisteban constituían una auténtica herramienta de primera mano para la gestión de la propia Casa Ducal en sus tres principales órganos administrativos: Secretaría, Contaduría y Archivo. Hecho que podemos generalizar y aplicar en su totalidad a cualquier Casa de la alta nobleza española. 
Concretamente el inventario que aquí nos interesa es el que lleva por título Libro del Estado de Medellín que, aunque no lleva fecha, fue elaborado a mediados del siglo XVIII. Encuadernado en tafilete marrón "con sus fundas de vadana [sic]" y con grecas y decoración vegetal grabada en oro fino, al clásico estilo barroco español, con formato de marca mayor y broche-cierre metálico, el tomo se compone de 571 páginas manuscritas, de las que se utilizaron las primeras 296.

No hubo necesidad de emplear la segunda parte del inventario o suplemento, que se inicia en la página 302 con el índice repetido bajo las palabras autógrafas de Brochero "para los papeles que se ofrezcan en adelante".

Abre el inventario el escudo de los Portocarrero, Condes del estado, seguido de una copia extractada de la merced del señorío de Medellín dada por el infante Enrique (fututo Enrique IV) a Rodrigo Portocarrero (1439) y de la tabla-índice de materias en las que el tomo quedó estructurado.

Todo hace indicar que a mediados del siglo XVIII ya había culminado M. A. Brochero la labor orgánica de los fondos de los diversos estados de la Casa de Santisteban del Puerto, incluidos los del condado de Medellín, excepción hecha de los del condado de Cocentaina que no llegaron a Madrid hasta el año 1751.

La valoración final al trabajo orgánico del primer archivero del conjunto documental de estos Benavides podemos calificarla solo de aceptable. En el debe de Brochero queda fundamentalmente la creación, en la clasificación, de series muy vagas e imprecisas (que serían, más adelante, parcialmente corregidas por otros archiveros) $^{65}$. Las regestas que compuso fueron tan extensas, en la mayoría de los casos, que hacían perder el hilo del extracto (cantidad informativa que, al menos aquí, no es sinónimo de calidad en la transmisión de datos). Por otro lado, el sistema de orden impuesto en la organización documental no sirvió para mantener el rigor cronológico deseado en la disposición de los fondos, aunque este criterio cronológico era el que se había buscado previamente. En su disculpa cabe indicar la inmensa tarea que realizó, cuantitativamente hablando, por sí solo y con escasísima ayuda ${ }^{66}$.

Una vez concluida la etapa de Brochero como archivero en 1773, ese mismo año el Archivo Ducal de Santisteban quedó reglamentado por las Instrucciones dadas desde Aranjuez, el 8 de junio de ese mismo año ${ }^{67}$ por D. Antonio de Benavides, XIII Conde de Medellín y II Duque de Santisteban, al poco de nombrar nuevo archivero mayor a D. José Manuel de la Vega (1773-1782) ${ }^{68}$, una fase transitoria en el depósito desde el punto de vista orgánico ${ }^{69}$.

Y con el relevo en la jefatura de la Casa de Santisteban-Medellín, en 1782, al suceder $\mathrm{D}^{\mathrm{a}}$. Joaquina María de Benavides y Pacheco, también debió declinar la

65 Esto repercutió en que, aún en nuestros días, resulte complejo localizar un determinado documento dentro del fondo.

66 Brochero no contó con un oficial, ni siquiera con algún copista. Él es quien describe todos y cada uno de los documentos, quien escribe de su puño los 15 inventarios que compuso, incluido el de Medellín, y quien transcribe muchos diplomas que lo requerían. Fue escasa, por tanto, la ayuda que recibió de la Casa Ducal y mucho lo que se le exigió, al contrario -por ejemplo- que a su sucesor en el cargo.

67 ADM, Santisteban, 39-2 (expd. 5: doc. inserto en la ratificación de 26 de marzo de 1799, que tuvo dicha Instrucción).

68 Véase Sánchez, 2015: 140-144. Una comparación de este reglamento con otro del Archivo Ducal de Medinaceli, elaborado el mismo año, en Sánchez, 2016.

69 Este archivero, en realidad, aportó muy poco (Sánchez, 2015: 131-133). 
gestión de J. M. de la Vega a cargo del Archivo, ascendiendo en el oficio D. Manuel de Terán (1783-1802), que era oficial del mismo desde $1780^{70}$. Este sería el artífice de la conclusión y complementariedad de la organización documental de los fondos del Archivo ${ }^{71}$, con innovaciones intranscendentes, si bien su labor apenas afectó al fondo del condado de Medellín, que se mantuvo por entonces en el estado en que lo había dejado Brochero.

Entrado el siglo XIX, con la agregación de la Casa de Santisteban a la de Medinaceli personalizada en el duque heredero D. Luis Joaquín Fernández de Córdoba y Benavides, además XV Conde de Medellín, se va a producir un intento de homogeneización de los fondos de un Archivo y otro (Santisteban y Medinaceli), ambos en Madrid, sobre todo a raíz de la transferencia del primero, en 1818, al palacio de los Medinaceli en el Paseo del Prado ${ }^{72}$. Por orden ducal de 4 de abril de ese año, el Archivo de Santisteban se incorporaba así al de Medinaceli, bajo la dirección única del archivero D. Juan Gil de Arana, ocupando una dependencia aparte, aledaña al antiguo depósito, en el propio palacio del Prado ${ }^{73}$.

Ya a fines del mismo siglo XIX, se va a consumar la organización total de los fondos y su descripción general. Así, cuando se realizó un recuento global de la documentación de los depósitos archivísticos del palacio del Prado (Sánchez, 2014: 97) por parte del archivero-bibliotecario de los duques de Medinaceli D. José María Octavio de Toledo en $1886^{74}$, se daba en este caso la circunstancia excepcional de que el fondo concreto del condado de Medellín se hallaba fragmentado en dos secciones de la misma denominación, sin ningún matiz diferenciador externo que no fuera la distinta ubicación que tenía cada una en el depósito del Archivo Ducal de Medinaceli, según su dispar procedencia.

Por un lado, estaba la sección que podemos considerar principal, por cuanto que se correspondía con el mayoritario fondo del condado metelinense agregado a la Casa de Santisteban del Puerto, que se agrupaba en 27 legajos custodiados en cuatro papeleras (enumeradas del 1 al 4, si bien esta última estaba vacía), como recogemos aquí.

ADM, Santisteban, 39-2 (expds. 5 y 7).

Véase Sánchez, 2015: 133-139.

Más datos en Sánchez, 2015: 149-160.

3 Arana fue un leal servidor de la Casa pues defendió los Archivos y todo el patrimonio ducal como si fuera suyo durante los difíciles años de la guerra de la Independencia (véase Sánchez, 2015: 152-167).

74 El Archivo Ducal de Medinaceli, en su conjunto, estaba entonces integrado en 42 secciones, con 3.864 legajos, 502 libros y 37 documentos sueltos, que se custodiaban en las 460 papeleras del depósito. 
Tabla 3. Disposición del fondo del condado de Medellín en el Archivo Ducal de Medinaceli proveniente de la Casa de Santisteban del Puerto (1886)

\begin{tabular}{|c|c|c|c|c|}
\hline SIGNATURA & SERIES & $\begin{array}{c}\mathrm{N}^{\circ} \\
\text { LEGAJOS }\end{array}$ & $\begin{array}{c}\mathrm{N}^{\circ} \\
\text { DOCS. } \\
\text { SUELTOS }\end{array}$ & $\begin{array}{c}\mathrm{N}^{\circ} \\
\text { LIBROS }\end{array}$ \\
\hline Papelera $1^{\mathrm{a}}$ & Papeles varios & 1 & & \\
\hline Idem & Papeles sin tejuelo & 1 & & \\
\hline Idem & Papeles sin colocar & 1 & & \\
\hline Idem & Papeles sueltos & 4 & & \\
\hline Papelera $2^{\mathrm{a}}$ & $\begin{array}{l}\text { Papeles pertenecientes a la villa de } \\
\text { Medellín y su condado (Legajos } 1 \text { a } 6 \text {, } \\
8,13,14,17 \text { y 19) }\end{array}$ & 11 & & \\
\hline Papelera $3^{a}$ & $\begin{array}{l}\text { Idem (Legajos 7, 9, } 10 \text { a 12, 15, 16, } 18 \\
\text { y 20) }\end{array}$ & 9 & & \\
\hline Papelera $4^{\mathrm{a}}$ & ---vacía--- & & & \\
\hline
\end{tabular}

Fuente: ADM, Manuscritos e impresos, antiguo "leg. 14. Archivo Ducal". Elaboración propia

Por otro lado, estaba también el minoritario fondo condal de Medellín llegado al depósito de los Medinaceli agregado a la Casa de Aytona, que se agrupaba en 7 legajos, custodiado en una sola papelera (concretamente la que llevaba el número 43 de la Casa de Aytona), tal como también aquí mostramos.

Tabla 4. Disposición del fondo del condado de Medellín en el Archivo Ducal de Medinaceli proveniente de la Casa de Aytona (1886)

\begin{tabular}{|c|l|c|c|}
\hline SIGNATURA & SERIES & $\begin{array}{c}\text { N }^{\circ} \\
\text { LEGAJOS }\end{array}$ & N $^{\circ}$ LIBROS \\
\hline Papelera 43 & Pleitos sobre sucesión & 2 & \\
\hline Idem & Villa de Villarejo de Fuentes & 1 & \\
\hline Idem & Papeles de su Administración & 1 & \\
\hline Idem & Testamentos, patronatos, etc. & 1 & \\
\hline Idem & $\begin{array}{l}\text { Posesiones, poderes, donaciones, } \\
\text { etc. }\end{array}$ & 1 & \\
\hline Idem & Censos & 1 & \\
\hline
\end{tabular}

Fuente: ADM, Manuscritos e impresos, antiguo "leg. 14. Archivo Ducal". Elaboración propia

Por aquellos años se abría un nuevo ciclo archivístico en el depósito ducal, bastante generalizado entre la nobleza española coetánea, que nosotros 
denominamos de la "Desvinculación señorial"75y que hoy tiene el depósito ducal. Este nuevo ciclo trajo consigo una serie de intervenciones archivísticas sobre los fondos consistente, por un lado, en un cambio en cuanto a las unidades de instalación hacia un sistema más abierto, por otro, en un reajuste de las secciones documentales del depósito - que afectó a la documentación del condado de Medellín-y, por último, en una modificación en el sistema de descripción archivístico, estableciendo incluso los cauces para la futura archivación del conjunto (Sánchez, 2014: 104-109).

El cambio en el modo de instalación documental de los depósitos del Archivo General de los Medinaceli consistió en la sustitución de las antiguas papeleras a legajos -los mismos que hoy conserva el depósito- que se colocaron en estanterías abiertas, con lo que se modificaba la tradicional reconditez y el hermetismo que habían caracterizado a los fondos durante el Antiguo Régimen por un sistema más abierto y visible. Dicho cambio se produjo a fines del siglo XIX y se materializó por el archivero D. Antonio Paz y Mélia, que fuera jefe del Departamento de Manuscritos de la Biblioteca Nacional y miembro del cuerpo de Archiveros, Bibliotecarios y Anticuarios españoles. El mismo archivero realizó algunas modificaciones en las secciones del depósito, como fue unificar los fondos de estados que se mantenían separados en secciones distintas dentro del conjunto (Sánchez, 2015: 184). Fue el caso de la documentación del condado de Medellín, hasta entonces custodiada en dos secciones distintas bajo con la misma denominación, por la dispar procedencia ya comentada de entrar en la Casa de Medinaceli, por un lado, a través de la Casa de Camiña en 1729 y, por otro, de la Casa de Santisteban del Puerto en 1818. Desde entonces se mantuvo la sección unificada bajo denominación de "Medellín", con 16 legajos, hasta nuestros días.

De la descripción realizada y el estado actual de la sección Medellín se desprende el cuadro de clasificación del antiguo fondo que recogemos (Tabla 5).

Tabla 5. Cuadro de clasificación final del Fondo documental. Elaboración propia

\section{GESTIÓN DE LA DOCUMENTACIÓN}

1.1. Apuntamientos: informes de los archiveros y decretos del Archivo

2. DESCENDENCIA Y SUCESIÓN

2.1. Árboles genealógicos

2.2. Dotes, dispensas y capitulaciones matrimoniales

2.3. Testamentos, codicilos y depósitos de cadáveres

2.4. Facultades, fundaciones y agregaciones de mayorazgos.

2.5. Hijuelas y particiones de bienes. Testamentarías

3. PATRIMONIO

3.1. Títulos de dominio y jurisdicción del condado

3.2. Términos del estado y de sus pastos y dehesas

3.3. Pertenencias y bienes sueltos del estado de Medellín

75 Se trata del período que arranca con la abolición de los mayorazgos y de los señoríos jurisdiccionales, que coincide con la entrada del régimen político del liberalismo en España, en el que la nobleza sufre una gran transformación que afectó también a sus Archivos (véase Sánchez, 2017 b). 
3.4. Mayorazgo de la villa y estado de Villarejo de Fuentes (Cuenca)

3.5. Posesiones

4. PATRONATOS, CAPELLANÍAS Y OBRAS PÍAS

4.1. Monasterio de San Juan Bautista de Medellín

4.2. Oratorio de los Condes

4.3. Capellanías en la Parroquia de Santa Cecilia de Medellín

4.4. Convento de la Concepción de Medellín

5. DOCUMENTACIÓN DE RECUENTO Y CONTROL

5.1. Inventarios de bienes o hacienda

5.2. Inventarios de escrituras

6. PRIVILEGIOS, MERCEDES Y DIGNIDADES

6.1. Correspondencia real de los condes

6.2. Oficios y servicios prestados a la Corona

7. ADMINISTRACIÓN Y CONTABILIDAD

7.1. Oficios y oficiales del condado

7.2. Juros consignados a lanzas

7.3. Censos redimidos, cargas contra el estado y pleitos de acreedores censualistas

7.4. Cuentas, concursos de acreedores y cartas de pago

7.5. Alcabalas, diezmos y tercias

7.6. Penas de cámara y bienes mostrencos

7.7. Portazgo del río Guadiana

8. PLEITOS

8.1. Pleitos por la posesión del estado

8.2. Pleitos y litigios por las ferias de Medellín

9. VARIOS

8.3. Pleitos sobre dehesas del estado

9.1. Correspondencia de valija diplomática

9.2. Encomiendas de órdenes militares

9.3. Encomiendas de indios de Huamachuco e indios vacos en el Perú

9.4. Cartas particulares.

Así estructurada es como se ha transmitido la documentación del condado de Medellín hasta nuestros días.

\section{Conclusiones}

Este antiguo fondo documental se compone de varios centenares de diplomas, custodiados hoy en su mayor parte en esos 16 legajos del Archivo de la Fundación Casa Ducal de Medinaceli, más algunas piezas sueltas o pequeñas series distribuidas en otras secciones -también de estados señoriales con los que la Casa de Medellín tuvo relación parental- como las de "Santisteban"76 y "Camiña"77, así como en la

76 ADM, Santisteban, leg. $13 \mathrm{n}^{\circ} .2$; leg. $28 \mathrm{n}^{\text {os }} .12$ a 30; y leg. $39 \mathrm{n}^{\circ} 2$ (varios expedientes).

77 ADM, Camiña, leg. $2 n^{\circ} .6$ bis. 
miscelánea denominada "Archivo Histórico" ${ }^{78}$ y en la sección facticia de "Privilegios rodados" $^{79}$, todas del mismo depósito.

A fines del siglo XIX y en los comienzos del XX, con el archivero Paz y Mélia, pasaron a formar parte de dicha miscelánea histórica la serie documental del fondo Medellín referida a la correspondencia real y particular de algunos condes de aquel estado extremeño, así como un grupo de reales cédulas y provisiones de concesión de títulos y otros privilegios, además de abundante correspondencia de valija diplomática de algunos condes $^{80}$ y duques ${ }^{81}$, aparte otra correspondencia y documentación sobre funciones gubernativas desempeñadas por algunos de estos nobles en Italia, Perú etc. ${ }^{82}$.

Parte de esta documentación ya ha sido dada a conocer, pero queda mucho camino por recorrer en el estudio de este fondo pues solo se ha avanzado en aspectos muy parciales ${ }^{83}$, estando pendiente hacer una obra de conjunto de este condado extremeño.

Del antiguo fondo metelinense, el Archivo de la Casa Ducal de Medinaceli conserva como instrumento de descripción útil aquel antiguo inventario de Brochero denominado Libro de Estado de Medellín de mediados del siglo XVIII, refrendo de cuando se organizó la mayor parte de la documentación del estado, junto con las fichas catalográficas realizadas por Paz y Mélia a fines del siglo XIX que aún se conservan. El propio sistema orgánico que se estableció en este fondo -como en el resto del Archivo- con la documentación descrita, pieza a pieza, en las carpetillas o "guardas" de cada documento, que realizaron los distintos archiveros que llevaron a cabo aquel trabajo orgánico, corregida y completada después por el propio Paz y Mélia, ayuda a la identificación y conocimiento del contenido de toda esta documentación.

Sirva, además, de contribución al conocimiento de este antiguo fondo la guía que incluimos nosotros aquí en Anexo, con descripción de sus series, las fechas extremas y la signatura de localización de los documentos, como aportación para quien necesite la consulta de esta documentación extremeña que forma parte del Archivo General de la Fundación Casa Ducal de Medinaceli.

\section{Referencias bibliográficas}

Alfonso X (1972 /edic. 1807). Las Siete Partidas del rey don Alfonso El Sabio. Madrid: Ediciones Atlas.

Almagro Gorbea, M.; García Muñoz, T. (2013). La leyenda del Conde de Medellín: ¿de un mito tartesio al 'Segismundo' de La vida es sueño? Revista de estudios extremeños, tomo LXIX, nº. 3, 1471-1493.

\footnotetext{
ADM, Archivo Histórico, legs. 74, 75, 80 y 81, más 272 (antigua caja de hierro 2) nº. 35-R, entre otros. ADM, Privilegios Rodados, $n^{\text {os }} .92$ y 94.

80 Del V Conde Pedro Portocarrero (años 1609-1610), y de sus homónimos el VIII (años1641-1669) y IX Conde (años 1640-1678). Véase ADM, Archivo Histórico, leg. $81 \mathrm{n}^{\text {os }}$. 1-31.

81 De los Condes Manuel y Antonio de Benavides, I Duque y II Duque de Santisteban del Puerto, respectivamente. Véase ADM, Archivo Histórico, leg. $80 \mathrm{n}^{\text {os }}$. 49-74.

82 ADM, Archivo Histórico, leg $74 \mathrm{n}^{\text {os }} .10$ a 15, y leg. $75 \mathrm{n}^{\text {os }} . \mathrm{n}^{\text {os }} .1$ a 40, más leg. $80 \mathrm{n}^{\text {os }} .1$ a 28.

83 Por ejemplo, del conde que fue virrey del Perú (Sánchez, 2016b) y otros ya referidos.
} 
Barcelos, Conde de: Nobiliario de D. Pedro, Conde de Bracelos, hijo del rey D. Dionis de Portugal. Ordenado y ilustrado con notas y índices por Iuan Bautista Lavaña, coronista mayor del reyno de Portugal. Roma: por Estevan Paolinio, 1640.

Braamcanp Freire, A. (1927). Livro primeiro dos Brasões de Sintra. Coimbra: Imprenta da Universidade.

Cabrera Muñoz, E. (1985). Beatriz Pacheco y los orígenes del condado de Medellín. Anuario de Estudios Medievales, 15, 513-551.

Caetano de Sousa, A. (1736). História genealógica da Casa Real Portugueza. Tomo II. Lisboa Occidental: Officina de Joseph Antonio da Sylva, impresor da Academia Real.

Clemente Ramos, J. (1990). La sociedad rural extremeña (s. XII-XIII). Revista de estudios extremeños, 46 (3), 541-558.

Cortés González, D. (2016). La fundación del mayorazgo sobre las villas del Condado de Medellín por Rodrigo Portocarrero y Beatriz Pacheco. Revista de Historia de las Vegas Altas. 8, 66-72.

www.academia.edu/26076306/La_fundaci\%C3\%B3n_del_Mayorazgo_sobre_las_villas _del_Condado_de_Medell\%C3\%ADn_por_Rodrigo_Portocarrero_y_Beatriz_Pacheco [Consulta: 11/11/2019].

Felgueiras Gayo, M. J. da Costa (1940). Nobiliário de Famílias de Portugal. Impressão diplomática do original manuscrito existente na Santa Casa de Misericórdia de Barcelos, Portugal, Agostinho de Azevedo Meirelles e Domingos de Araujo Affonso, 28 tomos. Braga: Oficinas Gráfica da Pax, 1938-1941. Tomo XXIV.

Fernandes, F. R. (1972). A extinção da descendência varonil dos Menezes de Albuquerque em Castela e suas implicações na administração do seu património em Portugal. Revista da Faculdade de Letras, História, Universidade do Porto, 1, 1453-1467.

Fernández de Bethencourt, F. (1900). Historia genealógica y heráldica de la Monarquía Española, Casa Real y Grandes de España. Tomo II. Madrid: Establecimiento Tipográfico de Enrique Teodoro.

Franco Silva, A. (2007). Las intrigas políticas de Juan Pacheco, del combate de Olmedo a la muerte de Juan II (1445-1454). Anuario de Estudios Medievales, 37 (2), 597-652.

Franco Silva, A. (2009). Las mujeres de Juan Pacheco y su parentela”. Historia. Instituciones. Documentos, 36, 161-182.

García Carraffa, A. y A. (1954). Enciclopedia heráldica y genealógica hispanoamericana. Tomo 72. Madrid: Imp. Antonio Marzo.

García Sánchez, F. (1997). La Condesa de Medellín, Da. Beatriz Pacheco. Don Benito: Gráficas Sánchez Trejo S.L.

García Sánchez, F. (2000). El Castillo de Medellín. Don Benito: Gráficas Sánchez Trejo S.L. Gomes, R. Costa (1995). A Corte dos Reis de Portugal no final da Idade Média. Lisboa: Difel.

González Gómez, A. (1976). Moguer en la Baja Edad Media. Huelva: Diputación Provincial de Huelva.

Grassotti, H. (1987). El repostero en León y Castilla (siglos XII-XIV). Cuadernos de Historia de España, 69, 41-76.

Labrador Arroyo, F. (2006). La Casa Real Portuguesa de Felipe II y Felipe III: La articulación del Reino a través de la integración de las élites de poder (1580-1621). 2 vols. Tesis Doctoral: Universidad Autónoma de Madrid.

Ladero Quesada, M. Á. (1997). La Casa Real en la Baja Edad Media. Historia. Instituciones. Documentos, 25, 327-350.

López de Haro, A. (1622). Nobiliario genealógico de los Reyes y Títulos de España. Tomo I. Madrid: Por Luis Sánchez, impressor real. 
Martínez y Martínez, M. R. (1904). Historia del reino de Badajoz durante la dominación musulmana. Badajoz: Tipografía y librería de Antonio Arqueros.

Mazo Romero, F. (1980). El condado de Feria (1394-1505). Contribución al estudio del proceso señorializador en Extremadura durante la Edad Media. Badajoz: Institución Cultural Pedro de Valencia.

Morel-Fatio, A. (1904). Un grand d'Espagne, agent politique de Louis XIV, en Etudes sur l'Espagne, III ${ }^{\mathrm{e}}$ série, VII. París: E. Bouillon, 211-228.

Ortega y Cotes, I. J. (1759). Bullarium Ordinis Militiae de Alcantara...: per annorum seriem nonnullis donationum. Madrid: Ex Typographia Antonii Marin.

Peña Izquierdo-Portocarrero, A. R. (2000). El linaje de los Portocarrero: de la Alta Edad Media al siglo XVI. Ariadna, 16, 7-80.

Pino García, J. L. del (1991). Extremadura en las luchas políticas del siglo XV. Badajoz: Diputación Provincial.

Pizarro, J. A. de Sotto Mayor (1987). Os Patronos do Mosteiro de Grijo: Evolução e Estrutura da Familia Nobre Séculos XI a XIV. Oporto.

Pizarro, J. A. de Sotto Mayor (1999). Linhagens medievais portuguesas: genealogias e estratégias (1279-1325). 3 vols. Porto: Universidade Moderna (Colecção Estudos de Genealogia, Heráldica e História da família, 3).

Reglero de la Fuente, C. M. (2001). Señores y vasallos en una aldea castellana medieval: Fuenteungrillo (siglos XIII-XIV). Edad Media: Revista de Historia, 4, 113-139.

Ribot García, L. (2018). El IX conde de Santisteban (1645-1716). Poder y ascenso de una Casa noble a través del servicio a la Corona. Espacio, Tiempo y Forma31, 23-42.

Salazar y Acha, J. de (2000). La casa del Rey de Castilla y León en la Edad Media. Madrid: Rumagraf S.A.

Sánchez González, A. (1990). Fondos documentales portugueses en el Archivo Ducal de Medinaceli en Sevilla, en II Jornadas de Historia sobre Andalucía y el Algarbe, Siglos XIII-XVIII. Sevilla: Universidad de Sevilla, 83-95.

Sánchez González, A. (2009). La colección de Privilegios Rodados originales del Archivo Ducal de Medinaceli (1175-1458). Lope de Barrientos. Seminario de Cultura, 2, 217-279.

Sánchez González, A. (2014). El Archivo de los Adelantados de Andalucía (Casa de Alcalá). Sevilla: Universidad de Sevilla.

Sánchez González, A. (2015). El Archivo de los Caudillos del reino de Jaén (Casa de Santisteban del Puerto). Jaén: Diputación de Jaén - Instituto de Estudios Giennenses.

Sánchez González, A. (2016a). Dos desconocidos reglamentos de archivos. Vegueta: Anuario de la Facultad de Geografía e Historia, 16, 481-506.

Sánchez González, A. (2016b). Papeles de ida y vuelta del virrey del Perú Diego de Benavides (1660-1666), en El Archivo General de Indias: El valor del documento y la escritura en el gobierno de América. Madrid: Ministerio de Cultura, 239-250.

Sánchez González, A. (2019). El Archivo del marquesado de Alcalá de la Alameda. Documenta \& Instrumenta, 17, 147-173.

Sánchez González, A. (2020). Un fondo documental en España sobre los Meneses de Portugal. Traiciones y lealtades a la Monarquía. Boletim do Arquivo da Universidade de Coimbra, en prensa.

Solano de Figueroa y Altamirano, J. (1650). Historia y santos de Medellín. Madrid: Francisco García y Arroyo Imprenta del Reyno. 
Anexo.- Tabla guía general del fondo Condado de Medellín en el Archivo Ducal de Medinaceli

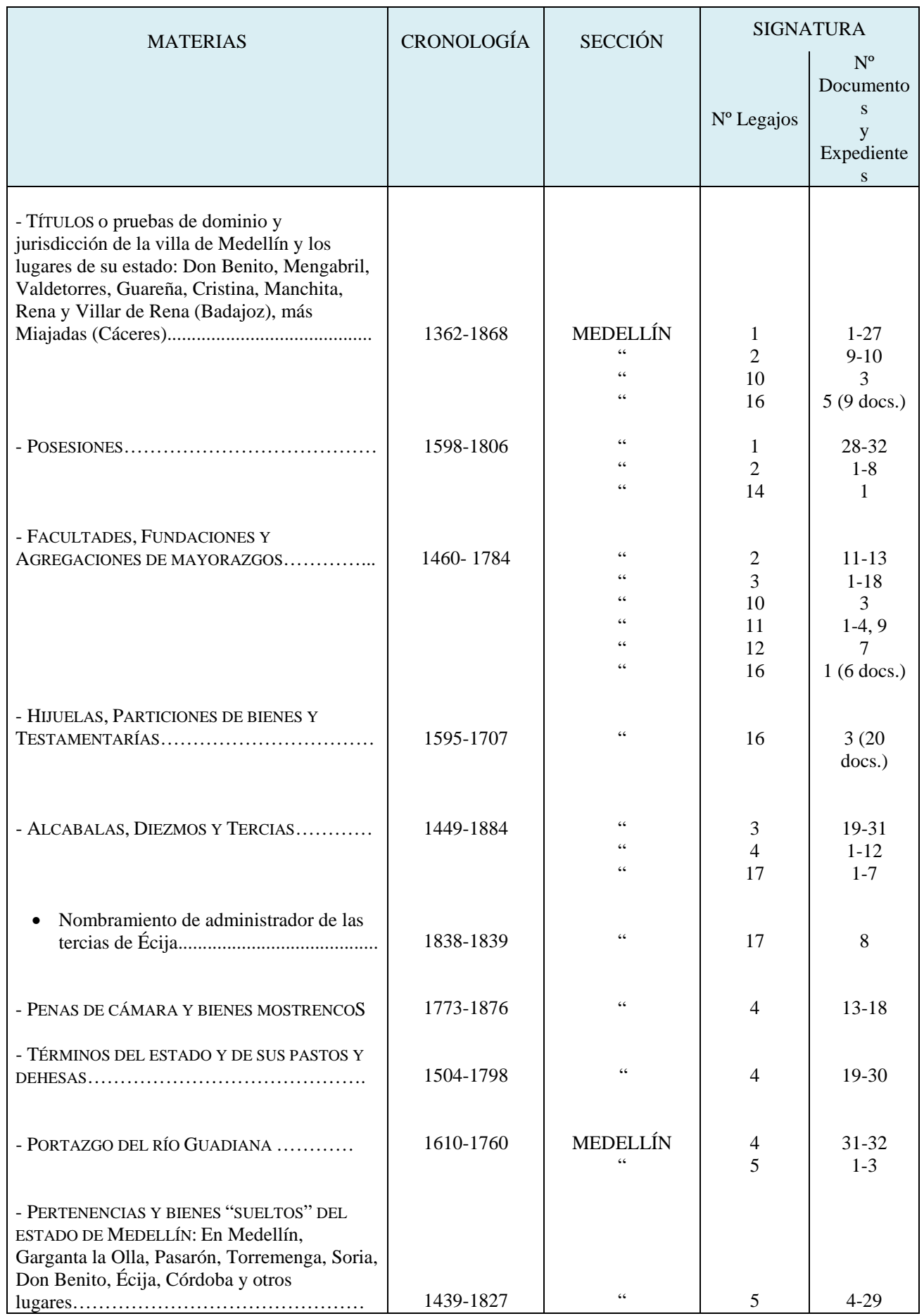




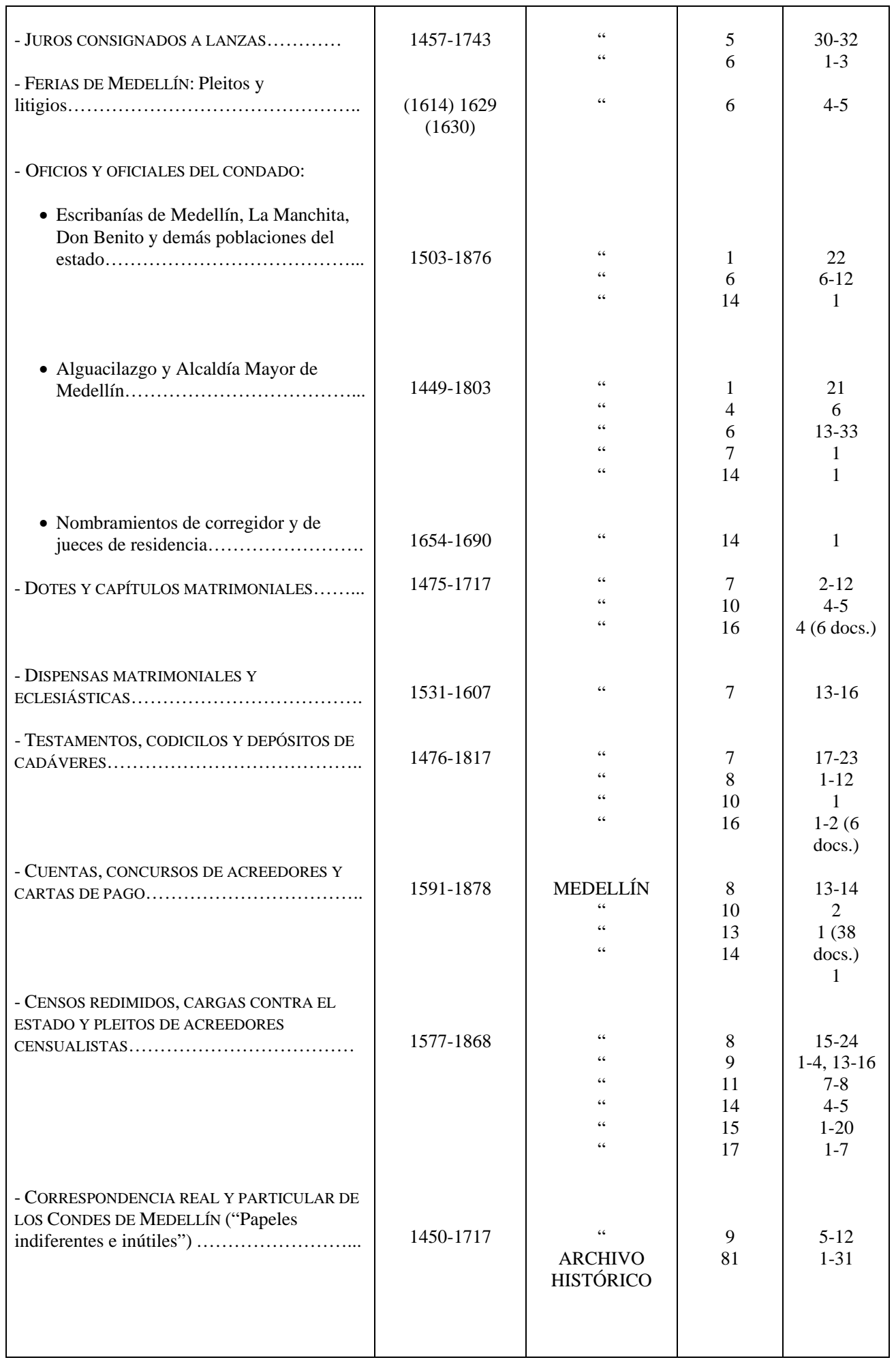


- Cartas particulares (correspondencia de algunos Condes) y "otros papeles en que nada interesa la Casa” (relaciones genealógicas, embargos de bienes, censos, inventarios de escrituras, etc.) ... - Pleitos:

- Por la posesión del estado de Medellín entre el Conde de Santisteban del Puerto y el Marqués de Aytona.

- Sobre censos de la legítima de Da . María Osorio y familia Monroy con el Marqués de Buscaloyo.

- Sobre dehesas del estado (La Veguilla, Remondo, Camachos y otras) y sobre asuntos varios.

\section{- INVENTARIOS:}

- De bienes o hacienda.

- De escrituras del Archivo:

- Del estado de Medellín y documentación de la Casa de Santisteban del Puerto.

· Del estado de Medellín y documentación de la Casa de Camiña....

\section{- PATRONATOS, CAPELLANÍAS Y OBRAS PÍAS:}

- Monasterio de San Juan Bautista de Agustinas recoletas, oratorio de los Condes y capellanías en la parroquia de Santa Cecilia, en Medellín....

Siglos XVII-
XVIII MEDELLÍN

Siglos XVIXVIII

S. f. (Siglo XVIII)

1625-1744

- Convento de la Concepción de Medellín.

\section{- APUNTAMIENTOS:}

(1541) - s.f. (Siglo XVII)

- Árboles genealógicos de los señores de la Casa de Medellín. 


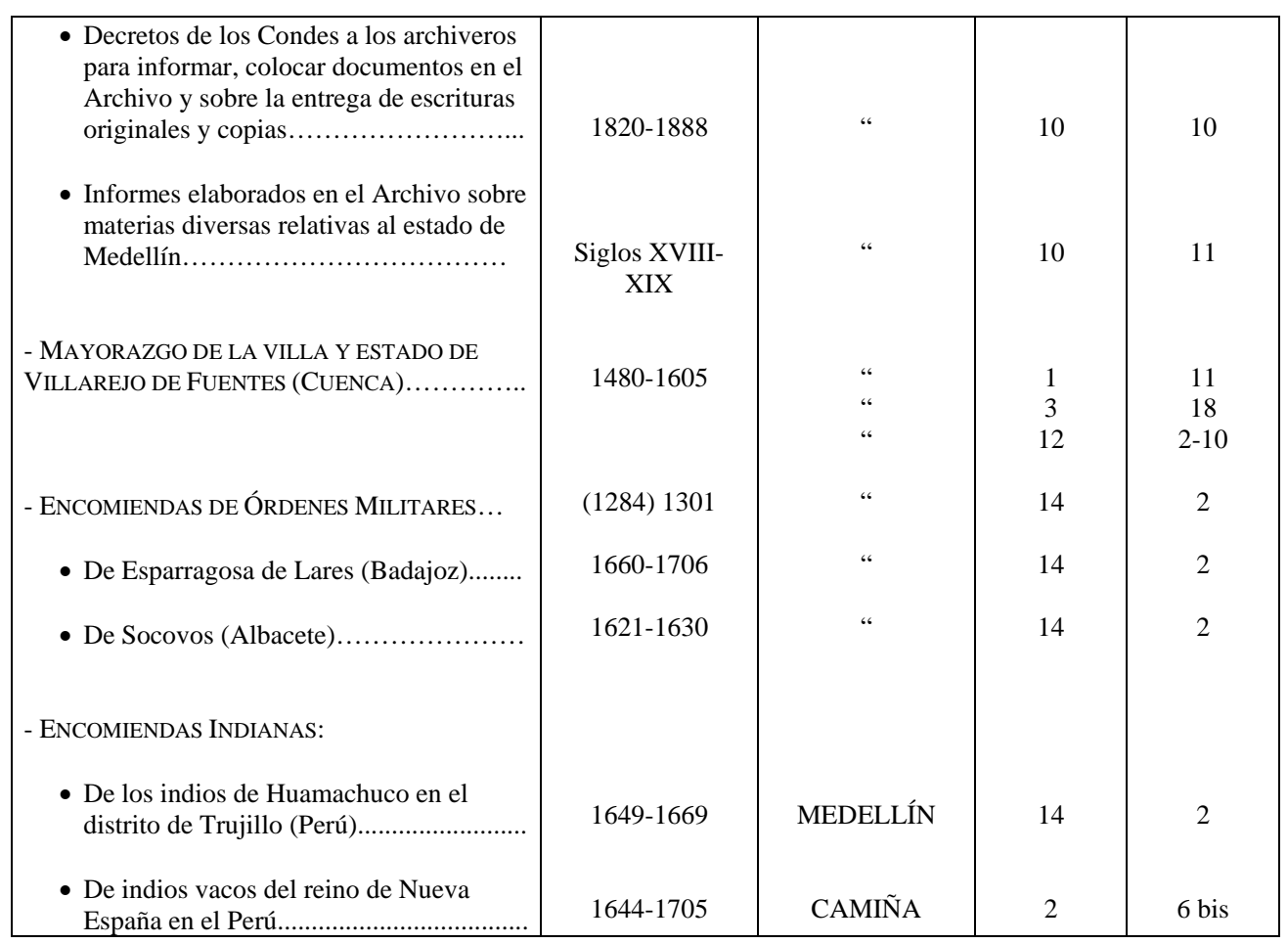

